\title{
DISCRIMINACIÓN POR ORIENTACIÓN SEXUAL EN EL SISTEMA ESCOLAR CHILENO: 2009 - 2016
}

\author{
DISCRIMINATION BY SEXUAL ORIENTATION IN THE SYSTEM \\ CHILEAN SCHOOL: 2009 - 2016
}

\author{
DISCRIMINAÇÃO POR ORIENTAÇÃO SEXUAL NO SISTEMA \\ ESCOLAR CHILENO: 2009 - 2016
}

Juan Cornejo ESPEJO ${ }^{1}$

RESUMO: O artigo apresenta os resultados de uma pesquisa realizada com base no registro de queixas de discriminação baseada na orientação sexual e identidade de gênero do MINEDUC nas escolas chilenas, no período 2009-2016. Atraves de tabelas apresentam-se as características e distribuição das queixas a nível nacional, além das questões mais recorrentes que as justificam. E, embora seja reconhecido que o referido cadastro foi um avanço no processo de visibilidade da homofobia escolar, não se pode ignorar que, dada a natureza burocrática do sistema, a totalidade das reclamações não resultou em sanções ou na implementação de medidas preventivas efetivas. Conclui-se tambèm, que ainda há um longo caminho a percorrer para eliminar a homofobia nas escolas, especialmente por causa dos preconceitos de professores e gestores, sem mencionar a falta de preparação dos professores para lidar com a diversidade sexual.

PALAVRAS-CHAVE: Homofobia. Discriminação. Queixas. Escolas chilenas

RESUMEN: El artículo presenta los resultados de una investigación realizada en base al catastro de denuncias de discriminación por orientación sexual e identidad de género del MINEDUC en escuelas chilenas, en el período 2009 - 2016. A través de tablas se presentan las características y distribución de las denuncias a nivel nacional, además de los temas más recurrentes que las justifican. Y si bien se reconoce que el citado catastro fue un avance en el proceso de visibilización de la homofobia escolar, no se puede obviar que, dado lo burocrático y engorroso del sistema, la totalidad de las denuncias no derivó en sanciones o implementación de medidas preventivas efectivas. Se concluye, además, que aún faltan mucho para eliminar la homofobia de las escuelas, especialmente por los prejuicios de los profesores y directivos, sin contar con la falta de preparación del profesorado para lidiar con la diversidad sexual.

PALABRAS CLAVE: Homofobia. Discriminación. Denuncias. Escuelas chilenas

\footnotetext{
${ }^{1}$ Profesor de Historia / Licenciado en Ciencias Sociales / Bachiller en Teología. Magíster en: Historia / Ciencia Política / Educación / Cs. Sociales. Doctor en Ciencia Política / Doctor en Estudios Americanos. Académico de la Facultad de Ciencias de la Educación - Universidad Católica del Maule. ORCID: <https://orcid.org/0000-0002-6436-0908>. Correo: jcornejo@ucm.cl
} 
ABSTRACT: The article presents the results of an investigation carried out based on the register of complaints of discrimination related to sexual orientation and gender identity of the MINEDUC in Chilean schools, in the period 2009-2016. Tables present the characteristics and distribution of complaints at the national level, in addition to the most recurrent issues that justify them. And while it is recognized that the aforementioned cadastre was an advance in the process of visibility of school homophobia, it can not be ignored that, given the bureaucratic and cumbersome nature of the system, the totality of the complaints did not result in sanctions or implementation of effective preventive measures. It also concludes that there is still a long way to go to eliminate homophobia in schools, especially because of the prejudices of teachers and administrators, not to mention the lack of teacher preparation to deal with sexual diversity.

KEYWORDS: Homophobia. Discrimination. Complaints. Chilean schools.

\section{Introducción}

Tradicionalmente el sistema escolar chileno ha tendido a invisibilizar las diferencias, especialmente cuando ellas remiten a estudiantes disidentes sexuales y/o de género del ideario heterosexista; ya sea, a través del disciplinamiento de los cuerpos y del binarismo, ya sea, a través de discursos moralizantes que buscan en el mejor de los casos desincentivar cualquier transgresión del orden heteronormativo o abiertamente reprimir cualquier disidencia en el entorno escolar. En ese contexto las burlas, la exposición al ridículo, la violencia escasamente disimulada, el control permanente y la autorrepresión funcionan como dispositivos disuasivos eficaces, cuyo fin último es convertir tanto a víctimas como a victimarios en guardianes de ese orden, mediante la trivialización de un cierto sentido común que legitima y perpetúa los discursos y prácticas homofóbicas.

Papel clave en ese ordenamiento escolar represivo cumplen los profesores. Ellos son los transmisores privilegiados de la ideología heterosexista que no sólo relega al plano de la anormalidad, del desvío, la perversión o del pecado cualquier expresión de la sexualidad que escape a los estrechos márgenes del heterosexismo, sino también los instrumentos visibles de la represión escolar presente en el currículo, las prácticas pedagógicas y las relaciones interpersonales.

A tal grado llegan los dispositivos represores que aún los estudiantes que deciden "salir del closet" continúan siendo tratados como heterosexuales, haciendo caso omiso de sus inclinaciones, deseos, amores o aspiraciones. Esto es, la escuela continúa haciendo de cuentas en sus discursos y en sus prácticas cotidianas que todos son o deberían ser heterosexuales por medio de una suerte de "heterosexualidad compulsoria"

RIAEE - Revista Ibero-Americana de Estudos em Educação, Araraquara, v. 13. n. esp. 2, p. 1471-1502, set., 2018. ISSN: 1982- 
(RICH, 2010; NAVARRO; SWAIN, 2010), que niega toda posibilidad de realización erótico - afectiva a los disidentes (CORNEJO, 2010); consagrando con ello no sólo una jerarquía de las sexualidades (BORRILLO, 2001), sino que legitimando distintas formas de violencia donde el silenciamiento opera verdaderamente como una "pedagogía del closet” (parafraseando el texto de E. K. Sedgwick (1998), Epistemología del armario).

Siendo ese el marco epistémico por el que transita el sistema escolar chileno el capítulo intenta problematizar acerca de los alcances de los procesos y dispositivos represivos de las disidencias presentes en las denuncias de discriminación por orientación sexual e identidad de género registradas por el Ministerio de Educación (MINEDUC) en el período 2009 - 2016.

\section{Antecedentes de la discriminación homofóbica en las escuelas chilenas}

La homofobia es una realidad que siempre ha estado presente en los sistemas escolares, especialmente en países en los que la escuela es un instrumento de configuración y mantención del orden establecido. En Chile, la escuela no sólo ha sido un elemento de conformación de la identidad nacional, sino también de la ideología heterosexista. Durante mucho tiempo, la escuela, junto con la familia y la religión, han dictado las normas que regulan los géneros y sexualidades permitidas.

En un contexto en el que la heterosexualidad y todas sus manifestaciones son exaltadas y colocadas a como ejemplo a seguir, las disidencias sexuales y genéricas son castigadas, silenciadas o invisibilizadas por los sistemas escolares formales. La pregunta que surge entonces es que hacer con aquellos estudiantes disidentes de ese orden o con "sexualidades en fuga" (MORGADE; ALONSO, 2008). Con el propósito de conocer las respuestas que ha dado el sistema escolar chileno a las disidencias sexuales se analizan las denuncias de discriminación por orientación sexual e identidad de género tanto desde el punto de su frecuencia como del tenor de las denuncias, a fin de develar las lógicas que explican los tentativas normalizadoras, invisibilidadoras y silenciadoras.

En este sentido cabe señalar que los datos se seleccionaron a partir del catastro general de denuncias de discriminación disponibles, que desde el año 2009 a la fecha ha venido realizando el MINEDUC. A partir de ese universo de datos se seleccionaron las denuncias de discriminación por orientación sexual e identidad de género, que en total suman 140 casos. Básicamente se trata de denuncias realizadas en las distintas oficinas del MINEDUC a lo largo de todo el país. Las quejas fueron ordenadas de acuerdo al 
sexo de las víctimas, la persona que realiza la denuncia, la distribución regional, el nivel educacional de las víctimas, el tipo de escuela, etc.

Además de los datos que ayudan a configuran un mapa de la discriminación homofóbica en el sistema escolar, se agruparon y analizaron los argumentos que motivan las denuncias. De ese análisis resultaron 7 ítemes, los cuales son resultado de las anotaciones que hace el funcionario del MINEDUC que acogió la denuncia. Los temas más recurrentes son los siguiente: presunción de una orientación sexual distinta a la heterosexual, humillación pública o ridiculización, castigo de las expresiones erótico - afectivas en público entre los estudiantes del mismo sexo, incitación a la homosexualidad, discursos religiosos homofóbicos, presencia de elementos homofóbicos en documentos oficiales de las escuelas y razones absurdas o difícilmente explicables.

Estos elementos constituyen señales claras de la homofobia cultural (BLUMENFELD, 1992) e institucional presente en las escuelas chilenas; además de negación, omisión e invisibilización de la diversidad sexual del espacio escolar. Es decir, prácticas que no son casuales y que, sin duda, constituyen en sí mismas expresiones de violencia homofóbica (FERNANDES DINIS, 2011).

Desde mediados de la década pasada, motivado por la mayor sensibilidad social, el aumento de la violencia en los distintos establecimientos educacionales del país y el deseos del MINEDUC de modernizar la legislación escolar vigente, se comienza a gestar la idea de crear una nueva normativa legal que regulase la convivencia escolar al interior de las escuelas y liceos de modo de prevenir y sancionar los hechos de violencia $^{2}$. Tal iniciativa se plasmó en la Ley 20.536 Sobre Violencia Escolar, promulgada en Septiembre de 2011.

Entre sus propósitos destacan la necesidad de promover el desarrollo armónico de los estudiantes y su inserción activa y participativa en la sociedad, en el sentido de ejercitar a los y las estudiantes en cómo vivir y relacionarse con los demás en los distintos espacios de interacción.

Esta política se fundamentaba en tres ejes esenciales. Un enfoque formativo que subraya la urgencia de enseñar a convivir con otros. La necesidad de participación y

\footnotetext{
${ }^{2}$ Insumo importante en el proceso de diagnóstico de los alcances de la violencia escolar en las escuelas del país fue la Encuesta Nacional de Convivencia Escolar, llevada a cabo por el MINEDUC durante en octubre de 2011 en 5.855 establecimientos con estudiantes de Octavo Básico.
} 
compromiso de toda la comunidad educativa. Y el reconocimiento de que todos los actores de la comunidad educativa son sujetos de derechos y responsabilidades.

El objetivo general de la política es orientar las acciones, iniciativas y programas que promuevan y fomenten la comprensión y el desarrollo de una convivencia escolar inclusiva, participativa, solidaria, tolerante, pacífica y respetuosa, en un marco de equidad de género y con enfoque de derechos. Ideas que han sido ratificadas por la actual política nacional de convivencia escolar (MINEDUC, 2015).

En un intento por frenar los hechos de violencia escolar, ya desde el año 2009, el MINEDUC había adoptado una serie de medidas tendientes a tener un catastro de denuncias a nivel nacional de esas situaciones, además de poner a disposición de los establecimientos una serie de materiales pedagógicos que sirvieran de base para la prevención.

Ese material, progresivamente, se fue focalizando en el curso de los años, en la formación en convivencia escolar, orientaciones para la elaboración de reglamentos internos de convivencia escolar, prevención de la violencia escolar (particularmente del bullying), prevención del maltrato y abuso sexual infantil, promoción de las escuelas inclusivas, programas de apoyo a la gestión del clima y convivencia escolar, y orientaciones para la elaboración de los proyectos educativos institucionales. Ese material complementó, asimismo, con otros dirigidos al abordaje de la sexualidad y afectividad, e inclusión del género como objetivo transversal prioritario del sistema educacional nacional.

En lo que dice relación con el catastro de denuncias de violencia escolar desde el año 2009 se crearon distintas plataformas y protocolos que acogieran los reclamos de las comunidades educativas y usuarios particulares, además de poner a disposición las propias oficinas ministeriales regionales y provinciales del MINEDUC donde poder hacer efectivas las denuncias y adoptar las medidas remédiales o correctivas correspondientes.

El llamado de las autoridades a hacer las denuncias buscaba tornar visible los hechos de violencia entre estudiantes (bullying) y entre estos y profesores ( $\mathrm{u}$ otros agentes educativos), además de evidenciar acciones o situaciones discriminatorias hacia determinados estudiantes os grupos de ellos. Básicamente las denuncias se tendieron a concentrar en aquellos aspectos que guardaban relación con las distintas expresiones de la discriminación, la violencia escolar (bullying) y las medidas de las autoridades educacionales consideradas arbitrarias por parte de los estudiantes y sus padres. 
Los criterios de acuerdo a los cuales se agruparon las denuncias de discriminación fueron los siguientes: por déficit atencional, por discapacidad física y/o intelectual, por características físicas y apariencia personal, por embarazo y maternidad, por problemas de salud (VIH, epilepsia), por opción religiosa, por inmigrante o distinto origen racial y por orientación sexual. A partir del 2015 se comenzó a distinguir entre orientación sexual e identidad de género, que originalmente estaba contenida en la primera.

Cabe consignar que toda estas iniciativas se vieron fortalecidas con la Ley Antidiscriminación (20.609), promulgada en Septiembre de 2012. Ley que si bien ya hacía varios años era tramitada en el Congreso Nacional (desde el año 2003), era resistida especialmente por sectores religiosos y la derecha política más conservadora.

La razón de la dilación, pese a haber consenso en la mayor parte de los articulados en todos los sectores políticos, era la inclusión de la orientación sexual como uno de los elementos más recurrentes de la discriminación y exclusión en la sociedad chilena. En este sentido numerosas encuestas en la última década dan cuenta de ello, entre las que destaca la VII Encuesta Nacional de Juventud (2012), donde se mencionaba a tres grupos de la población que estaba particularmente expuestos a la discriminación por su condición de minoría: los homosexuales y bisexuales (en primer lugar), personas con alguna discapacidad y aquellos que pertenecen a un pueblo originario (p. 130). A su vez en la VIII Encuesta Nacional de Juventud (2015) se señalaba que del total de jóvenes que declaraban ser homosexuales o bisexuales, el 15\% de ellos reportaba sentirse discriminado por su orientación sexual, siendo el segundo grupo prioritario de jóvenes que se han sentido más discriminados (p. 160).

A juicio de los sectores más conservadores la discriminación o violencia motivada por la orientación sexual, siguiendo ciertos supuestos filosóficos moralizantes, no sólo no constituía una violación de derechos, sino que era expresión de una conducta y afectividad desordenada y antinatural.

El estupor e indignación que provocó en la opinión pública nacional la agonía y posterior muerte de un joven homosexual (Daniel Zamundio), brutalmente golpeado por un grupo de jóvenes aparentemente neonazis (marzo de 2012), precipitó las discusiones y pronta promulgación de la citada ley, que además de incluir la orientación sexual como una posible causal de discriminación consideró la identidad genérica como otro elemento, eventualmente, desencadenante de hechos de violencia o discriminación. En otras palabras, a la ley contra la violencia escolar se sumó la ley antidiscriminación 
como ejes articuladores de la comprensión y diseño de las políticas y estrategias de la convivencia escolar en el país.

Con el propósito de canalizar las denuncias por violencia escolar (bullying), discriminación y medidas adoptadas por autoridades educativas en los distintos niveles del sistema nacional consideradas arbitrarias, el MINEDUC creo, como se comentó anteriormente, algunas plataformas y protocolos que facilitasen el registro, seguimiento y adopción de medidas remediales. Sin lugar a dudas, el catastro que sirvió de insumo a la Ley de Violencia Escolar se nutrió particularmente de las denuncias motivadas por el bullying escolar, al punto que la citada ley es conocida como "ley antibullying".

No obstante, un acápite especial de las denuncias son los actos considerados discriminatorios por los denunciantes, motivados por una orientación sexual e identidad de género disidente del orden heteronormativo.

En las siguientes páginas se presentarán los resultados de una investigación realizada en base a los datos oficiales del registro nacional de denuncias del MINEDUC por violencia escolar, particularmente aquellas referidas a la discriminación por orientación sexual e identidad de género en el sistema escolar chileno registradas en todo el territorio nacional, ya sea por padres y apoderados, ya sea por los propios estudiantes que manifiestan haber sido discriminados en sus establecimientos educacionales porque se presume una posible homosexualidad, por actitudes homofóbicas de parte de directivos, profesores, inspectores u otros estudiantes hacia jóvenes que explicitaron públicamente su orientación, o medidas arbitrarias adoptadas en su contra.

Los datos están desagregados por regiones, género de las víctimas, agentes de la denuncia, por la cuantía de los casos, tipo de establecimientos en el que se sucedieron los hechos denunciados y nivel de escolaridad de los sujetos implicados. En la parte final del estudio se hace una presentación del tenor de las denuncias, agrupando esos antecedentes en siete categorías que aluden a las razones que las justifican.

\section{Escuela: normalización, invisibilización y silenciamiento}

La escuela concebida como institución privilegiada de socialización cumple una serie de funciones de transmisión, preservación y producción de conocimientos. No obstante, esas no son sus únicas funciones. En una sociedad que ha convertido a la heterosexualidad en la norma y al binarismo y la reproducción en las fronteras de la 
realización erótico - afectiva, cualquier conducta o comportamiento que trasgreda o desborde los márgenes del heterosexismo es descalificada por medio de discursos pretendidamente científicos, especulaciones filosóficas esencialistas, o argumentos religiosos - moralizantes.

En ese escenario la escuela no sólo transmite y perpetúa esas creencias a través de sus políticas, sus prácticas pedagógicas y la propia cultura escolar, sino también a través de un cierto sentido común que concibe la diversidad sexual como una transgresión, desvío o anormalidad. Noción que es internalizada por los agentes educativos en tanto régimen de verdad incuestionable. Esto es, la escuela y sus agentes no sólo son los instrumentos de divulgación del heterosexismo, sino los guardines de ese mismo orden.

En este mismo sentido no se puede obviar tampoco que el currículo escolar, dada su disposición normalizadora, es un campo fértil para el disciplinamiento y control de las sexualidades, particularmente de las disidentes que se desarrollan a partir de lo que J. Butler (2008) denomina "matriz heteronormativa". Es decir, aquel orden que encuadra las relaciones, aún las homosexuales, a partir del modelo heterosexual.

La heterosexualidad emerge así, como el conjunto de normas prescritas (explícitas o no) que definen todo el orden social y no apenas la elección de la pareja sexual. Así, más que banalizar la heterosexualidad compulsoria, la heteronormatividad encuadra a los sujetos en una secuencia invariable cuerpo - sexo - género - sexualidad y los somete a las normas que regulan su pertenencia social (Butler, 2008). En otras palabras, la heteronormatividad rechaza a todos los sujetos con sexualidades no heterosexuales o con performances de género no binarias, catalogándolas como personas aberrantes y peligrosas. Los no heterosexuales harían parte del otro lado de la frontera, aquel que demarca lo que no se debe ser (SILVA, 2014).

Una de las consecuencias inmediatas de los proceso represivos y de rotulación son los esfuerzos de definición de una "identidad homosexual" que escapa a los propios sujetos identificados como tales, al punto que cualquier sujeto definido a partir de esa esencia puede ser reconocido dentro o fuera del grupo identitário. Dicho de otra forma, para ser representada cultural y socialmente la "identidad homosexual" requiere de un modo de ser que es también esencializada y normalizada.

En el entorno escolar el esfuerzo identitario se expresa a través de rituales y normas que dan vida al proyecto reproductor, cuya justificación se basa en la mantención de las tradiciones y la homogeneización, y en donde el control de los 
discursos es la forma preferida de establecer lugares de pertenencia entre lo que puede figurar intramuros y lo que debe permanecer fuera del espacio escolar. Así, lo que no se puede decir o se debe decir se torna en herramienta de control, que frecuentemente fuerza el silenciamiento (ERIBÓN, 2001; NÚÑEZ, 2011), al tiempo que alimenta una voluntad de saber que incentiva la proliferación de discursos que confieren materialidad a los sujetos y a las prácticas que consiguen decodificar y clasificar como posibles normas.

Desde ese modo el cuerpo escolarizado no es apenas el cuerpo del aprendiz. Se trata más bien de un cuerpo femenino o masculino que debe aprender a comportarse de acuerdo con lo que la naturaleza determina. Esto es, la sexualidad de la cual trata la escuela está circunscrita a la heterosexualidad, definiendo a todas las otras expresiones como lo anormal, lo que desafía la naturaleza, la aberración, lo invertido, lo pervertido, lo homosexual (SILVA, 2014).

Lo anterior incide directamente en la dificultad que evidencian los profesores para lidiar con las "sexualidades en fuga" (ALONSO; MORGADE, 2008) que escapan al binarismo heteronormativo presente en ciertos estudiantes. En este sentido la educación institucional desempeña un papel decisivo en el proceso de afirmación de algunas identidades consideradas naturales y deseables, en tanto que otras son vistas como problema cuya sola mención puede ser motivo de desestabilización. Y aún cuando la escolarización no es la única determinante en la producción de identidades sociales, no se puede negar que es través de sus proposiciones, imposiciones y prohibiciones que se conforman parte significativas de las historias personales (LOURO, 2007).

Por otro lado, la educación en tanto negociación de sentidos procesa la selectividad con la cual aprendemos a ver aquello que consideramos importante, enseña a discernir, clasificar y elegir como apropiados los conceptos y los modos de vida que puedan ser referenciados en los padrones normativos. Es decir, la escuela se constituye como un espacio - tiempo ritualizado, normalizado, generificado y sexualmente clasificatorio.

Desde el punto de vista de la enseñanza - aprendizaje la escuela produce un conocimiento capaz de modelar las prácticas sociales, direccionar y disciplinar las elecciones de modo de garantizar la eficacia del efecto normativo. La imposición de lo que entra o no en el currículo es hecha por medio de la inscripción de sistemas simbólicos de acuerdo con los cuales los sujetos deben interpretar, organizar el mundo y actuar en él. Siendo así, el currículo junto a las otras tecnologías escolares (arquitectura, 
mobiliario, libros, uniformes, etc.) se convierte en un elemento de producción cultural que construye, materializa, normaliza y modela las subjetividades más allá de la propia experiencia escolar.

El producto de eso es, por tanto, una individualidad autorregulada a partir de saberes de lo que es cierto o errado, fruto del conocimiento producido y divulgado en el espacio - tiempo escolar; pues, no sólo lo que se ve o lo que se dice cumple una función modeladora, aún la propia materialidad escolar está dotada de significados que se traducen en un sistema de valores, en un cierto orden, disciplina y vigilancia.

Este poder ejercido sobre el cuerpo constituye un ritual organizado que hace actuar de acuerdo a la norma. Se trata de una incursión capilar transmitida en los discursos y empoderamiento de los agentes autorizados para hablar, además del currículo que opera eficazmente como vehículo autorizado en la distribución de los poderes y en su utilización (VEIGA - NETO, 2002); pues, el currículo esta desde su origen intrínsecamente ligado a un proyecto social, por lo cual puede ser entendido como un "artefacto sociocultural", construido a partir del conocimiento considerado socialmente válido (GOODSON, 1995).

Dicho de otra forma, los alcances y límites del currículo están siempre condicionados por las contingencias y por los sujetos con los cuales precisa operar. El currículo puede ser visto entonces, como un mecanismo y un instrumento de poder en el cual se producen reglas y padrones de verdad que guían y gobiernan a los sujetos. En ese entendido, la escuela reafirma una disposición represiva (en la acepción foucultiana), según la cual la represión no debe ser vista apenas como prohibición o impedimento para la acción, sino como una productora de discursos que modelan cuerpos y corporalidades.

En este sentido, se puede afirmar fehacientemente que la escuela no es un mecanismo neutro en la (re)(des)construcción de los individuos. Sus códigos, símbolos, arreglos arquitectónicos son construidos a partir de discursos que demarcan lugares de ser para cada individuo, motivo por el cual ella no puede ser pensada apenas como el espacio de docilización de los cuerpos o la formación de los individuos, ella también está enmarcada en la red de micropoderes que envuelve la sociedad.

Es un espacio usado por el poder disciplinador como las demás instituciones sociales que intentan facilitar la internalización de valores morales y conductas para cada persona, cumpliendo de paso con una función disciplinadora que se práctica de forma invisible por medio de "técnicas normalizadoras del yo" y por el panoptismo que 
no es otra cosa que un dispositivo de vigilancia y autorregulación (BENTO; SILVA, 2015).

Con todo, no se puede considerar sólo el poder como un mecanismo que oprime, limita o sofoca. Él también produce, incita resistencias y reinvenciones. Y la escuela, en cuanto componente de esa tela de micropoderes es un espacio privilegiado para eso. Así, los grupos considerados subordinados pueden resistirse a la normalidad y a la hegemonía de las identidades impuestas consideradas normales, cuestionando su carácter natural y universal, promoviendo movimientos sociales que contradicen los discursos predeterminados o desnaturalizando los géneros, abriendo la posibilidad de tornarse hombres y mujeres plurales o aún no asumir ninguno.

Sin embargo, el silencio que es impuesto a los estudiantes también toca a los profesores, particularmente cuando se abordan asuntos que trasgreden las fronteras de la "normalidad". Pero no sólo el habla es silenciada, también los cuerpos los son, pues, no deben expresar ciertos gestos, deben permanecer distantes y sin contacto directo con los estudiantes. Es decir, la escuela es un espacio intelectual centrado en la cabeza pensante, ya el cuerpo debe ser controlado por ser el lugar en que se alojan las emociones, las sensibilidades y la lívido (BENTO; FELIX-SILVA, 2015).

Un cuerpo disciplinado por la escuela es entrenado en el silencio en un determinado modelo de habla; concibe y usa el tiempo y el espacio de una forma particular. Manos, ojos y oídos están adiestrados para las tareas intelectuales, pero posiblemente desatentos o no entrenados para otras tantas (LOURO, 2007, p. 21).

$\mathrm{Y}$ es en ese universo de restricciones, invisibilizaciones y silenciamiento donde pareciera debatirse y tensionarse los manejos dados a aquellos estudiantes que no se encuadran o se resisten a un orden impuesto, ya sea por decisión propia, ya sea por el temor homosexual que paraliza, y cuyo corolario es un catastro de denuncias de discriminación homofóbica que no hacen sino develar las contradicciones y aflicciones de un sistema escolar que se declara inclusivo y democrático, pero que se conforma y acostumbra a convivir con la exclusión.

\section{Discriminación por orientación sexual e identidad de género en el sistema educacional chileno en cifras}

Uno de los tópicos más recurrentes entre las denuncias realizadas ante el MINEDUC entre el 2009 y el 2016 es el que se refiere a la discriminación por 
orientación sexual en establecimientos educacionales del país de distinta dependencia. Del análisis del catastro se desprende que la gran mayoría de los casos denunciados aluden a esta causa, y no a la discriminación por identidad de género.

La razón de ello es que, presumiblemente, se tiende a confundir la identidad de género con la orientación sexual como si fuesen una misma realidad o porque las comunidades educativas desconocen o son menos sensibles a las problemáticas que enfrentan las personas con una identidad de género que no se corresponde con su sexo biológico.

Además, dentro de la conceptualización "discriminación por orientación sexual” se incluyen aquellos hechos que responden, mayoritariamente, a situaciones de violencia escolar u hostigamiento que bien podrían ser catalogadas como "bullying homofóbico"3 o situaciones que aluden a posturas ideológicas, expresadas en juicios de valor de agentes educativos, en relación a la homosexualidad.

\section{Medios a través de los cuales se canalizan las denuncias}

Tabla 1: Denuncias en el período en estudio

\begin{tabular}{|l|c|c|c|}
\hline & Oficinas del MINEDUC & $\begin{array}{l}\text { Web site del } \\
\text { MINEDUC }\end{array}$ & $\begin{array}{l}\text { Total de denuncias en el periodo } \\
2009-2016\end{array}$ \\
\hline Frecuencia & 105 & 35 & $\mathbf{1 4 0}$ \\
\hline Porcentaje & 75 & 25 & $\mathbf{1 0 0}$ \\
\hline
\end{tabular}

Fuente: creación propia a partir del registro de denuncias del MINEDUC 2009-2016

Como se puede apreciar en la tabla anterior el mayor número de denuncias se realizó a través de las oficinas regionales y provinciales del MINEDUC. Y aún cuando en sus inicios de publicitó que las denuncias podían ser hechas a través del sitio web del Ministerio o a través de una línea telefónica especialmente habilitada para ese propósito, en la práctica se obligaba a los denunciantes a ratificar la denuncia personalmente, con lo cual se limitaban las posibilidades de denunciar actos o situaciones discriminatorias hacia estudiantes de zonas rurales, ciudades más pequeñas o apartadas que no eran

${ }^{3}$ En el contexto Hispanoamericano una de las pioneras en el uso del término "bullying homofóbico" fue la profesora española Raquel Platero (2007; 2007), que lo define en los siguientes términos: "[...] El bullying son aquellos comportamientos violentos por los que un alumno o alumna se expone y/o queda expuesto repetidamente a la exclusión, aislamiento, amenaza, insultos y agresiones por parte de sus iguales, una o varias personas que están en su entorno más próximo, en una relación desigual de poder, donde los agresores o bullies se sirven de la homofobia, el sexismo, y los valores asociados al heterosexismo (2007, p. 5).

RIAEE - Revista Ibero-Americana de Estudos em Educação, Araraquara, v. 13. n. esp. 2, p. 1471-1502, set., 2018. ISSN: 1982- 
capitales regionales o provinciales. Ello, probablemente, explique en parte, como veremos más adelante, que haya regiones que no registren denuncias de discriminación por orientación sexual e identidad de género. Es más, la denuncias no sólo debían ser hechas en dichas oficinas sino que una vez que se iniciaba el proceso investigativo, que normalmente solía durar varios meses en el mejor de los casos, debían ser ratificadas nuevamente con lo cual las posibles sanciones o acciones reparatorias llegaban a destiempo o cuando las víctimas habían abandonado el sistema escolar, perdiendo toda efectividad la denuncia o posibilidad de cambio de las condiciones que generaban la discriminación.

\section{Denuncias en el período en estudio}

Tabla 2: Número de denuncias por año

\begin{tabular}{|l|c|c|c|c|c|c|c|c|c|}
\hline & 009 & 010 & 011 & 012 & 013 & 014 & 015 & 016 & otal \\
\hline Frecuencia & & 4 & 8 & 9 & 2 & 9 & 5 & 0 & $\mathbf{4 0}$ \\
\hline Porcentaje &, 1 & 0 & 2,8 & 0,7 &, 5 & 3,5 & 7,8 & 4,2 & $\mathbf{0 0}$ \\
\hline
\end{tabular}

Fuente: creación propia a partir del registro de denuncias del MINEDUC 2009-2016.

Como se puede apreciar en la tabla, progresivamente el número de denuncias se ha ido incrementando en todo el país. La razón se explica no sólo por el mayor conocimiento respecto de las distintas plataformas de denuncia en la opinión pública nacional, sino también por la mayor conciencia social respecto de los derechos de las personas LGBTI.

Llama la atención que el mayor número de denuncias en el período se registró el 2012, probablemente, motivada por la conmoción pública que generó el caso Zamudio que motivó a muchos jóvenes y sus familias a visibilizar las situaciones discriminatorias de que eran víctima en sus establecimientos. Con todo, los años 2015 y 2016 le siguen en el número de denuncias, evidenciando con ello no sólo un mayor empoderamiento y consciencia de derechos de los estudiantes disidentes, sino que un crecimiento sostenido.

\section{Sexo de las víctimas}


Tabla 3: Sexo de las víctimas

\begin{tabular}{|l|c|c|}
\hline Hombre & Mujer & Total $(\mathbf{2 0 0 9}-\mathbf{2 0 1 6})$ \\
\hline 38 & 102 & $\mathbf{1 4 0}$ \\
\hline 27,1 & 72,8 & $\mathbf{1 0 0}$ \\
\hline
\end{tabular}

Fuente: creación propia a partir del registro de denuncias del MINEDUC 2009-2016.

La tabla muestra que el mayor número de personas que acusan ser víctimas de discriminación por orientación sexual en el sistema escolar chileno son mujeres. La explicación de ello, de acuerdo a lo que se desprende del registro de las denuncias, se debe a que las estudiantes o sus familias se muestran más conscientes de sus derechos o dispuestas a hacer pública su orientación. Los hombres en cambio, especialmente sus familias, parecieran querer mantener en secreto la orientación sexual de sus hijos, argumentando que son incomprendidos

Por los agentes educativos o sus actitudes son mal interpretadas. Sólo excepcionalmente asumen públicamente una orientación disidente del ideal heteronormativo.

Esa actitud de las familias de algún modo deja al descubierto su homofobia cultural, expresada tanto en su temor a la exposición pública como en la ausencia de cuestionamiento al orden heterosexista que genera la discriminación. Es decir, lo que cuestionan esas familias es el maltrato puntual que reciben sus hijos, pero en ningún momento atacan los fundamentos de un orden excluyente y discriminador, probablemente porque ellos mismos, sin decirlo comparten, los supuestos de ese orden.

\section{Persona que realiza la denuncia}

Tabla 4: Persona que realiza la denuncia

\begin{tabular}{|l|l|l|}
\hline Persona & Frecuencia & Porcentaje \\
\hline Apoderado(a) & 53 & 37,8 \\
\hline Padre / Madre & 26 & 18,5 \\
\hline Estudiante E. Básica & 6 & 4,2 \\
\hline Estudiante E. Media & 36 & 25,7 \\
\hline Universitario & 4 & 2,8 \\
\hline Director(a) & 4 & 2,8 \\
\hline
\end{tabular}




\begin{tabular}{|l|l|l|}
\hline Profesor(a) & 7 & 5 \\
\hline No señala & 4 & 2,8 \\
\hline & $\mathbf{1 4 0}$ & $\mathbf{1 0 0}$ \\
\hline
\end{tabular}

Fuente: creación propia a partir del registro de denuncias del MINEDUC 2009-2016.

De los datos reportados, como queda demostrado en la tabla, la mayor cantidad de denuncias fue realizada por el apoderado o tutor, seguida por el padre o la madre, y en tercer lugar por los propios estudiantes, particularmente de enseñanza media. La razón se explica por el grado de dependencia de las víctimas, en la totalidad de los casos menores de edad. En el caso de las denuncias llevadas a cabo por los propios estudiantes, queda de manifiesto tanto su empoderamiento, expresado en una actitud más proactiva, como por la mayor conciencia de derechos que tienen en general en la actualidad los estudiantes chilenos. El resto de los agentes denunciantes son bastante menos relevantes, posiblemente, por el distanciamiento respecto de los hechos denunciados.

\section{Denuncias por región}

Tabla 5: Denuncias por región

\begin{tabular}{|l|l|l|}
\hline Región & Frecuencia & Porcentaje \\
\hline Región Metropolitana & 78 & 55,7 \\
\hline Arica y Parinacota & 4 & 2,8 \\
\hline Tarapacá & 3 & 2,1 \\
\hline Antofagasta & 3 & 2,1 \\
\hline Coquimbo & 4 & 2,8 \\
\hline Valparaíso & 29 & 20,7 \\
\hline O’Higgins & 3 & 2,1 \\
\hline Maule & 4 & 2,8 \\
\hline Bío - Bío & 3 & 2,1 \\
\hline Araucanía & 3 & 2,1 \\
\hline De los Ríos & 3 & 2,1 \\
\hline De los Lagos & 3 & 2,1 \\
\hline & $\mathbf{1 4 0}$ & $\mathbf{1 0 0}$ \\
\hline
\end{tabular}

Fuente: creación propia a partir del registro de denuncias del MINEDUC 2009-2016 
La distribución de denuncias por regiones muestra que el mayor número de ellas tuvo lugar en la región Metropolitana, seguida por la región de Valparaíso. La explicación de esa distribución se debe a que esas regiones concentran a más de la mitad de la población nacional (aproximadamente el 60\%), son las más urbanizadas y las que concentran los canales más expeditos de información. No obstante, no deja de sorprender el caso de la región del Bío-Bío, que además de ser el núcleo poblacional más importante después de la región Metropolitana, en el periodo en estudio, solo registre tres denuncias.

Muy por debajo, con solo cuatro denuncias aparecen las regiones de Arica, Coquimbo y el Maule, el resto de las regiones registran apenas tres denuncias. Atacama y Aysén, por su parte, no tienen registros.

Esa distribución desigual de las denuncias, hegemonizada por la región Metropolitana, deja en evidencia que pese a las campañas de sensibilización del MINEDUC, las denuncias por discriminación por orientación sexual e identidad de género (como de otras formas de exclusión de los sistemas escolares formales) han resultado infructuosas, la información aún es insuficiente, se desconocen los canales y protocolos de denuncia y/o el temor a la exposición pública es aun significativa al punto de desincentivar cualquier reclamo ante una vulneración de derechos. Es decir, la homofobia, el heterosexismo y la autocensura que subvierten cualquier política inclusiva en el ámbito escolar, continúan imponiendo un régimen de exclusión que jerarquiza las sexualidades y es funcional a otras formas de exclusión y marginación social.

\section{Tipo de establecimiento}

Tabla 6: Tipo de establecimiento donde la discriminación tuvo lugar

\begin{tabular}{|c|l|l|}
\hline Tipo de establecimiento & Frecuencia & Porcentaje \\
\hline Particular pagada & 6 & 4,2 \\
\hline Particular subvencionada & 99 & 70,7 \\
\hline Municipal & 29 & 20,7 \\
\hline No señala & 6 & 4,2 \\
\hline & $\mathbf{1 4 0}$ & $\mathbf{1 0 0}$ \\
\hline
\end{tabular}

Fuente: creación propia a partir del registro de denuncias del MINEDUC 2009-2016 
De acuerdo a la dependencia de establecimiento, se concluye que el mayor número de denuncias, lejos, lo concentran los colegios particulares subvencionados; es decir, colegios administrados por particulares pero que reciben aportes económicos del Estado. Le siguen los colegios municipalizados.

Por su parte, el número de denuncias de los colegios particulares pagados dista mucho de los primeros. La razón de ello se explica por el tipo de manejo de situaciones conflictivas o de convivencia escolar que tienen estos establecimientos, o por la menor exposición pública con que suelen administrar sus conflictos; lo cual en ningún caso los exime de hechos de violencia escolar o discriminación.

\section{Nivel escolar donde tuvo lugar la discriminación}

Tabla 7: Nivel de escolaridad de las víctimas

\begin{tabular}{|l|l|c|}
\hline E. Básica & E. Media & Total $(\mathbf{2 0 0 9}-\mathbf{2 0 1 6})$ \\
\hline 41 & 99 & $\mathbf{1 4 0}$ \\
\hline 29,3 & 70,7 & $\mathbf{1 0 0}$ \\
\hline
\end{tabular}

Fuente: creación propia a partir del registro de denuncias del MINEDUC 2009-2016.

Las denuncias registradas en el período en estudio claramente dejan de manifiesto que ellas tienden a concentrase en la enseñanza media. Prácticamente se dobla el número en primero y segundo medio, si comparado con la educación básica.

En términos etarios el período más crítico para el bullying homofóbico es aquel que va desde los 12 a los 16 años. Presumiblemente un factor decisivo en la mayor prevalencia de las agresiones se explique por el proceso de transformación que están viviendo los estudiantes: de niños a adolescentes, con toda la carga emocional que ello supone y los problemas propios de una etapa de la vida donde se está redefiniendo la identidad individual.

En este sentido numerosos estudios muestran que la mayor incidencia de la violencia escolar y del bullying en particular tiene lugar durante los primeros años de la enseñanza básica y primeros de la enseñanza media (ZYSMAN, 2014; GIMÉNEZ DE ABAD, 2014; MAGENDZO, GONZÁLEZ, ESTÉVEZ, 2014; TOMAELLO, 2014). Esta información es coincidente con la proveniente de la encuesta nacional de convivencia escolar realizada con estudiantes de octavo básico durante el 2011. 


\section{Curso de la víctima}

Tabla 8: Curso de la víctima

\begin{tabular}{|l|l|l|}
\hline Curso & Frecuencia & Porcentaje \\
\hline Tercero Básico & 4 & 3,1 \\
\hline Cuarto Básico & 1 & 1,4 \\
\hline Quinto Básico & 3 & 2,1 \\
\hline Sexto Básico & 6 & 4,1 \\
\hline Séptimo Básico & 9 & 6,3 \\
\hline Octavo Básico & 12 & 8,4 \\
\hline Primero Medio & 24 & 16,8 \\
\hline Segundo Medio & 40 & 28,4 \\
\hline Tercero Medio & 22 & 15,7 \\
\hline Cuarto Medio & 19 & 13,6 \\
\hline & $\mathbf{1 4 0}$ & $\mathbf{1 0 0}$ \\
\hline
\end{tabular}

Fuente: creación propia a partir del registro de denuncias del MINEDUC 2009-2016

Por último, en lo que respecta al nivel escolar de los estudiantes denunciantes, claramente se advierte, que la gran mayoría de ellos corresponde a estudiantes de enseñanza media, concentrándose la mayor parte en primero y segundo medio. De igual modo, los denunciantes de enseñanza básica, mayoritariamente, corresponden a estudiantes de séptimo y octavo básico.

No deja de sorprender, asimismo, que en tercero y cuarto medio las denuncias tienden a descender, probablemente, por el proceso de maduración de los propios estudiantes.

\section{Tenor de las denuncias}

Básicamente el tenor de las denuncias de discriminación por orientación sexual e identidad de género, registradas por el MINEDUC en el período 2009 - 2016, pueden agruparse en siete categorías.

\section{a) Presunción de orientación sexual distinta a la heterosexual}

RIAEE - Revista Ibero-Americana de Estudos em Educação, Araraquara, v. 13. n. esp. 2, p. 1471-1502, set., 2018. ISSN: 1982- 
La denuncia más frecuente guarda relación con la presunción de homosexualidad. Padres y apoderados argumentan como causal recurrente de discriminación en establecimientos de distinta dependencia acusaciones de parte de directivos o profesores de hechos o actitudes que debelarían una cierta orientación sexual homosexual de algunos estudiantes. Situación que a juicio de los padres y apoderados denunciantes no estarían comprobadas.

Normalmente las denuncias apuntan a las medidas arbitrarias y no ajustadas a los procedimientos que establece el propio MINEDUC para la cancelación de matrículas que habrían adoptado ciertos establecimientos del país fundadas en la presunción de homosexualidad, Las medidas adoptadas suelen ser expulsiones, cancelación de matrícula o negación de cupo para el año lectivo siguiente.

Una de las prácticas que más molesta a los denunciantes son los extensos interrogatorios a que son sometidos ciertos jóvenes, especialmente por parte de profesores e inspectores, en búsqueda de una confirmación de una presunta homosexualidad. Esta práctica se complementa o viene a confirmar otra denuncia que apunta a la existencia de "listas negras" de homosexuales al interior de los establecimientos acusados de discriminación.

Otro aspecto que llama la atención es que en la casi totalidad de los registros de denuncias de estudiantes varones, las víctimas o sus padres no sólo no asumen una identidad no heterosexual sino que se sienten incomprendidos por los pares y poco acogidos por las autoridades de sus establecimientos.

\section{b) Humillación pública}

El segundo ítem que más se repite es la humillación pública a que habrían sido expuestas las víctimas. Tal humillación u ofensas habrían sido llevadas a cabo, en primer término, por los compañeros de la víctima, seguido por profesores e inspectores. La humillación pública se habría manifestado a través de amenazas, agresiones verbales, comentarios maliciosos o mal intencionados, insultos, injurias, etc. llegando en algunos casos a la violencia física.

Este tipo de agresiones es, probablemente, la más frecuente y la que deja marcas más profundas en la autoestima y subjetividad de las víctimas, al punto que la gran mayoría de ellos manifiestan que es un recuerdo doloroso e ingrato que los acompaña de por vida. 


\section{c) Por expresiones homo - afectivas en público}

Una de las quejas recurrentes es el malestar que sienten aquellos jóvenes que habiendo asumido públicamente una orientación no heterosexual y/o identidad de género no binaria y no ajustada a lo que se supone le corresponde de acuerdo a su sexo biológico, es la negación de parte de directivos, profesores e inspectores de esa nueva situación personal. Es decir, pese a haber asumido una realidad distinta a la esperada los distintos agentes educativos siguen haciendo de cuentas, en sus prácticas discursivas y de relacionamiento interpersonal que todos son o deberían ser heterosexuales. En este sentido la negación se configura como una práctica recurrente y una forma manifiesta de invisibilización de lo considerado diferente. Tal negación se traduce, entre otras cosas, en el rechazo y sanción institucional de cualquier expresión homo - afectiva pública de estos jóvenes. No son pocos aquellos que manifiestan que fueron sancionados (llegando en algunos casos a la expulsión del establecimiento), simplemente por haberse besado con algún compañero o compañera del mismo sexo.

La actitud poco tolerante, a juicio de los denunciantes, de parte de las autoridades de los colegios les parece poco inclusiva de la diversidad, al tiempo que odiosamente arbitraria; pues, se preguntan si los colegios permiten las expresiones hetero - afectivas porque no se hace lo mismo con manifestaciones de afecto entre personas del mismo sexo.

\section{d) Por inducir a algún compañero}

Otras de las denuncias más frecuentes ante el MINEDUC dice relación con una supuesta "mala influencia" que ejercerían ciertos jóvenes (varios de ellos declaradamente gays o lesbianas) sobre otros compañeros, a los cuales inducirían a seguir sus mismos pasos. Esto es, los inducirían a tornarse homosexuales, ya sea a través de relaciones amorosas homoeróticas, ya sea a través de la imitación de sus modos, hábitos o formas de vestir.

La queja de los padres de estos supuestos inductores, o de los propios jóvenes, es que si bien reconocen que sus hijos son asumidamente gays o lesbianas ello no implicaría necesariamente que fuesen una mala influencia para sus compañeros. A juicio de estos padres la acusación está basada en prejuicios y en montajes muy bien 
urdidos por parte de directivos, profesores e inspectores para justificar una expulsión ya decidida.

Además en la mayor parte de las denuncias consta el trato diferenciado que reciben aquellos jóvenes que públicamente se declaran gays o lesbianas, a los cuales normalmente se les cancela la matrícula o se los expulsa, respecto de aquellos otros que a los ojos de los directivos aparecen como las víctimas seducidas, a los cuales no se les impone ningún castigo o sanción, pese a haber sido igualmente sorprendidos en actos amorosos. Este trato desigual es, la mayor parte de las veces, el detonante que motiva la denuncia.

\section{e) Discursos religiosos homofóbicos}

Un tipo de denuncias de discriminación hacia jóvenes disidentes del orden heteronormativo, si bien relativamente escasas, es aquella presente en algunos establecimientos confesionales. Básicamente se trata de denuncias realizadas por

Estudiantes o sus padres que sienten vulnerados su derechos por parte de directivos y/o profesores de este tipo de establecimientos, cuyos discursos evidencian no sólo un marcado sello moralizante, sino descalificatorio del homoerotismo y discriminatorio de jóvenes y profesores LGBTI fundados en creencias o supuestos religiosos.

\section{f) Reglamentos de convivencia escolar que legitiman la discriminación por orientación sexual}

Otro tipo de denuncia, estrechamente vinculado al ítem anterior, presente en el catastro de violencia escolar del MINEDUC, que va más allá de situaciones puntuales apuntando más bien a condiciones estructurales que develan de alguna forma la homofobia cultural instalada en el seno de la escuela, y más específicamente en sus reglamentos de convivencia escolar, son las expresiones intolerantes o abiertamente discriminatorias hacia personas LGBTI, descalificación del homoerotismo o sanción de cualquier manifestación homo - afectiva contenidas en dichos documentos.

Coincidentemente, la mayoría de los reglamentos de convivencia escolar que contienen este tipo de expresiones son aquellos pertenecientes a establecimientos confesionales, pese a haber disposiciones claras del MINEDUC, en consonancia con la Ley Antidiscriminación, en el sentido de excluir cualquier disposición interna que 
pudiese avalar algún tipo de discriminación o arbitrariedad fundada en la raza, nacionalidad, situación socioeconómica, idioma, ideología, religión, sexo, orientación sexual, identidad de género, apariencia física, enfermedad, discapacidad, entre otras.

Cabe recordar, asimismo, que este tipo de denuncias no sólo es posible de ser hallado en el catastro de denuncias por violencia escolar del MINEDUC, sino que ha sido reportado en la prensa nacional o en periódicos on line vinculado a algunas agrupaciones LGBTI.

\section{g) Razones espurias}

Este ítem agrupa una multiplicidad de denuncias que van de aquellas que relatan que un estudiante de tercero básico habría sido marginado de su colegio en razón de la orientación sexual de la madre, a aquellas más frecuentes que señalan que ciertos establecimientos discriminarían a determinados jóvenes motivados por su apariencia física, su forma de vestir, de hablar o sus modales considerados afeminados o masculinizados por parte de algunos directivos, pese a no haber certeza de una orientación sexual distinta de la heterosexual.

Entre los argumentos más absurdos denunciados están aquellos relatos de algunos padres que señalan que sus hijos habrían sido discriminados en sus colegios "por tener sólo amigas" o "juntarse sólo con mujeres".

\section{Medidas disciplinarias adoptadas por los establecimientos denunciados}

Junto con las denuncias de discriminación los denunciantes sostienen que lo que más incómoda son las medidas disciplinarias adoptadas por los establecimientos. Medidas que no sólo resultan arbitrarias y no ajustadas a las normativas del MINEDUC, que desde hace ya varios años ha venido promoviendo la inclusión sin restricciones de todos los estudiantes al sistema escolar, sino que implican una clara trasgresión de la Ley Antidiscriminación.

Básicamente, las medidas pueden ser agrupadas en siete categorías. A continuación se exponen algunos extractos registrados por el funcionario del MINEDUC que acogió la denuncia y que dan cuenta de la situación denunciada:

1. Cancelación de matrícula 
"Apoderada denuncia discriminación de parte del establecimiento educacional. Le cancelan matrícula ( $1^{\circ}$ Enseñanza Media) por condición sexual (...)”.

"La madre denuncia discriminación hacia su hija, ya que la han dejado sin internado debido a que el establecimiento educacional informa a la madre que su hija tiene una amistad con otra alumna, lo cual no es bien visto a los ojos del Liceo, por lo tanto le han negado la matrícula al internado para el año 2011".

"Se presenta madre y apoderada de alumno que cursa $5^{\circ}$ de Enseñanza Básica (alumno nuevo), para dar a conocer que el colegio dispone la cancelación de matrícula (...), por problemas graves de homosexualismo, sin realizar investigación previa. Por juego besó a compañero de segundo piso".

\section{Expulsiones sumarias}

"Alumna denuncia que Liceo la discriminó por opción sexual, señala que no la han dejado entrar al Liceo se encuentra suspendida y la han amenazado con video que mostraría imágenes con su pareja”.

"Mi hija fue expulsada del Liceo porque la vieron dándose un beso con una alumna de $4^{\circ}$ medio".

3. Suspensiones provisorias o condicionalidad de la matrícula

“(...) fue suspendido por el director de este establecimiento por cinco días, motivado por su condición sexual”.

4. Cierre del año académico de forma anticipada

"Se presenta apoderado de alumna de $4^{\circ}$ Año de Enseñanza Media, antigua, para dar a conocer que se le cierran año escolar anticipado a contar del 31 de agosto, por su orientación sexual. Por este concepto, el establecimiento determina negarle opción de graduarse, actividades extraprogramáticas contempladas dentro del proyecto educativo”.

5. Sugerir o presionar a los padres a retirar a sus hijos del establecimiento

"La alumna denuncia que su madre fue presionada a retirarla, bajo amenaza de denunciar a la pareja de la alumna”.

6. Obligar a un estudiante acusado de homosexualidad a dar exámenes libres 
"Mi hijo tiene prohibida la entrada al colegio y fue obligado a dar exámenes libres".

7. Existencia de elementos o contenidos discriminatorios en manuales de convivencia escolar

"En su manual de convivencia este colegio discrimina a los alumnos con conductas homosexuales impidiéndoseles ser matriculados".

"En los estatutos del establecimiento se prohíbe el ingreso de alumnos con tendencia homosexual”.

Sin embargo, lo que más llama la atención es la actitud de algunos establecimientos, que ante el reconocimiento público de una identidad disidente del orden heteronormativo procuran por todos los medios expulsar al implicado, apelando al "mal ejemplo" que supone para la comunidad educativa una identidad disidente no autosilenciada.

"Apoderado denuncia discriminación hacia su hija y otros alumnos por su orientación sexual, además algunos inspectores realizan seguimientos y tienen listas negras".

"Inspector general dijo a compañeras que no se juntaran con el niño porque era gay, y las que lo hacían eran lesbianas (...)”.

"Inspector discrimina al niño porque es más amigo de niñas que niños. Lo acusa de hacer cosas que no corresponde a varones (...)”.

No obstante, los efectos que ocasiona el hostigamiento que acusan las víctimas y las consecuencias que devienen de él, contrariamente a lo que se pudiera pensar, no se origina inicialmente por el acoso de los pares sino de los directivos y profesores de los establecimientos denunciados. Es más bien el prejuicio e intolerancia de estos últimos, lo que incide en que los pares repliquen conductas discriminatorias e incurran en bullying homofóbico hacia sus compañeros disidentes sexuales.

\section{Efectos de la discriminación en las víctimas}

De lo que se desprende del registro de denuncias que constan en el catastro del MINEDUC los efectos de la discriminación por orientación sexual e identidad de género más frecuentes pueden ser agrupados en cuatro categorías: 
1. Psicosomáticos: expresados en malestares físicos, alteraciones del sueño, etc.

2. Psicoemociales: expresados en depresiones, alteraciones de carácter e incluso en intentos de suicidio.

3. Sociales: expresados en aislamiento y retraimiento.

4. Académicos: expresados en bajo rendimiento, deserción y reprobación escolar.

Los efectos antes descritos son plenamente coincidentes con lo que se afirma en la literatura especializada (BAKER, 2002; POTEAT, ESPELAGE, KOENIG, 2009; RIVERS, 2011; RUSSELL, 2011; RUSSELL, SINCLAIR, POTEAT, KOENIG, 2012; ROBINSON, ESPELAGE, RIVERS (2013), PENNA Y MATEO, 2014, PÉREZ, 2014), en estudios de organismos colegiados (American Educational Research Association (2013) y de organismos internacionales (UNESCO, 2012).

A este respecto cabe recordar que la American Educational Research Association (2013) sostiene que el bullying y la discriminación homofóbica no sólo es un problema de convivencia escolar sino que se ha convertido en un problema de salud pública, tanto por el daño psicoemocional e impacto en la subjetividad de las víctimas, como por la magnitud de los intentos de suicidios de jóvenes LGBTI. Por su parte, el estudio de UNESCO (2012), además de corroborar la información anterior, afirma que América Latina y Chile en particular son los lugares donde el bullying homofóbico está más arraigado en la cultura escolar.

Un alto porcentaje de estudiantes lesbianas, gays y bisexuales informaron la existencia de bullying homofóbico en Chile $(68 \%)$, Guatemala (53\%), México (61\%) y Perú (66\%). En Brasil más del $40 \%$ de los hombres informaron que habían sido agredidos físicamente en las escuelas [...] (UNESCO, 2012, p. 21).

Situación explicable por la homofobia cultural (Blumenfeld, 1992) e institucional, la escasa educación sexual (preferentemente moralizante), ausencia de ella (PALMA; REYES; MORENO, 2013) o decididamente el silenciamiento de las disidencias, y cuya expresión más elocuente se expresa en las denuncias antes analizadas, donde la sola reivindicación de una sexualidad en fuga es prontamente reprimida.

\section{Discusión}


Desde el punto de vista teórico y en consideración a los antecedentes presentados se concluye que la escuela en Chile, en general, además de ser un lugar de disciplinamiento (ALONSO; MORGADE, 2008; NÚÑEZ, 2011) con sus dispositivos escolares que tienden a la homogeneización y uniformización en tanto prácticas recurrentes de modelamiento y control se configura como un auténtico espacio de normalización, invisibilización y silenciamiento de las disidencias sexuales y genéricas. Situación que queda de manifiesto no sólo en las medidas disciplinarias adoptadas por ciertos establecimientos denunciados en sus intentos de contención de cualquier comportamiento, gesto o actitud que desborde los dictados del heterosexismo, particularmente cuando ellos cuestionan las "masculinidades hegemónicas" (Connell, 1995), sino también en sus esfuerzos por reprimir cualquier expresión erótico afectivas entre personas del mismo sexo, consideradas expresiones de sexualidades desviadas, anormales o patológicas, pero nunca verdaderas demostraciones de amor o de afecto.

Así, la "pedagogía del closet" se articula como un "cerco de inclusión heterosexual" (BEER, 2008), que establece los límites de la normalidad y lo deseable en materia de sexualidad, a la vez que niega toda otra posibilidad de realización humana a través de una serie de recursos que van desde los aparentes vacíos o descuidos curriculares relativos a la diversidad sexual en el ámbito de la educación sexual, hasta la violencia descarnada presente en la segregación, las burlas, la humillación pública o el bullying homofóbico. Motivos por el cuales se puede afirmar, como sostiene Lópes Louro (2007) que la homofobia es consentida y enseñada en la escuela.

A tal grado llega la negación y el silenciamiento escolar en el caso chileno que aún los estudiantes que han "salido del closet", continúan siendo tratados como si fuesen heterosexuales (JUNQUEIRA DINIZ, 2013), en clara demostración de una heterosexualidad compulsoria como la define Rich (2010), motivo por el cual esta misma autora llega a afirmar que el supuesto reconocimiento de la diversidad sexual y de género no es sino una "ilusión de alternativa"; pues, lo que ocurre en la práctica no pasa de una "tolerancia de lo inevitable" (CORNEJO, 2010). Esto es, se acepta a estos estudiantes en cuantos mantengan en las sombras del anonimato o en un closet de doble fondo sus abyectas inclinaciones.

Ante la imposibilidad de excluir por completo a los disidentes del sistema escolar se apela, como queda demostrado a través del estudio del registro de denuncias de discriminación homofóbica del MINEDUC ya analizado en los acápites anteriores, a 
medidas disciplinarias que van desde las reprimendas a las expulsiones sumarias en un intento concertado de silenciamiento.

Con todo, lo que más preocupa no son estas reacciones, hasta cierto punto esperables en un orden escolar heterosexista, sino el desenlace de los procesos de denuncias. Sin desconocer el enorme avance que supuso el contar con un canal donde poder plasmar las situaciones discriminación presentes en las escuelas y liceos del país, y consecuentemente tener un registro de denuncias de discriminación que permita dimensionar los alcances de la homofobia escolar, no se puede obviar que ninguna de ellas hasta el 2016 derivó en acciones o medidas concretas.

Los largos períodos de indagación en el caso de aquellas que fueron acogidas, la necesidad de ratificar por segunda vez la denuncia, la excesiva burocracia o la falta de voluntad de llevar adelante los procesos ha dado como resultado que en ninguno de los casos investigados se llegue a sanciones a los establecimientos u actos raparatorios hacia las víctimas. Como consta en el mismo catastro del MINEDUC, todas las causas han sido archivadas, ya sea porque las victimas denunciantes no perseveraron en la acción al cambiarse de establecimiento o egresar de cuarto medio, ya sea porque definitivamente desertaron del sistema escolar.

Es decir, el catastro de denuncias es un registro valioso desde el punto de vista de la información, pero no un instrumento eficaz de combate de la homofobia escolar, razón por la cual se puede afirmar que la escuela nacional continúa siendo un espacio privilegiado de normalización, silenciamiento e invisibilización de las disidencias.

\section{Conclusión}

El catastro de denuncias de discriminación por orientación sexual e identidad de género en el período 2009 - 2016 deja al descubierto no sólo un tipo de violencia específica, sobre el cual hay aún poca consciencia, sino un problema más profundo, tradicionalmente invisibilizado en el sistema escolar chileno, cual es la homofobia cultural e institucional presente en las escuelas y liceos nacionales. Invisibilización que por sí sola constituye una violencia, pero que a su vez es expresión de una ideología contenida en prácticas discursivas, de convivencia, representaciones y valoraciones sociales que tienden a descalifican, demonizar y/o sancionan cualquier expresión que escape a los márgenes del orden heteronormativo, erigido como ideal, especialmente para los jóvenes en proceso de formación. 
En este sentido el estudio presentado tiene la virtud de evidenciar una problemática que pareciera ir en aumento, no por una mayor incidencia respecto del pasado, sino por el despertar de la conciencia de violación de derechos de aquellos que asumen una identidad distinta de la heterosexual o se presume son homosexuales, así como del empoderamiento de esos mismos jóvenes y sus familias que parecieran no estar más dispuestos a ser discriminados por ser distintos.

Con todo, pese a ese despertar de conciencias, queda mucho camino por andar en el resguardo y protección de los estudiantes LGBTI al interior de los establecimientos educacionales del país. Por lo pronto, como se desprende del mismo catastro de denuncias del MINEDUC, no basta con el registro de las mismas. Se hace necesario una actitud más proactiva en la promoción y defensa de derechos de parte de todos los agentes educativos en todos los niveles del sistema escolar nacional, expresado en acciones concretas que contribuyan a la formación y educación para la convivencia con la diversidad.

En este sentido no es casual la queja de los profesores que están en el sistema como de los futuros profesionales de la educación en proceso de formación, que manifiestan no contar con la preparación suficiente para lidiar con estudiantes disidentes del ideario heterosexista, ni contar con las herramientas pedagógicas para hacer frente a situaciones de violencia escolar motivada por una orientación sexual o identidad de género no binaria. Vale decir, aún quedan tareas pendientes tanto en el plano estructural contenido en normativas preventivas específicas, promoción de una educación inclusiva y combate a toda forma de homofobia cultural. Desafíos que deberían ser integrados como ejes prioritarios en la formación de profesores.

El estudio devela además, la fuerte concentración de los mecanismos de denuncia en la región Metropolitana de Santiago, pese a la diversificación de canales, los cuales aparecen más bien como nominales tratándose de las regiones más apartadas que verdaderas oportunidades para el resguardo de derechos.

No deja de sorprender tampoco el tenor de las denuncias. Claramente se advierte en ellas que todavía prevalecen, tanto de parte de los acusados de discriminación como de la mayor parte de las familias de las víctimas ideas patologizantes, moralizadoras y aún criminalizadoras del homoerotismo. Los reparos y cuestionamientos contenidos en las denuncias no se detienen en la homofobia cultural e institucional que se advierte en las acciones o situaciones denunciadas, o en la arbitrariedad de las medidas represivas adoptadas por determinadas autoridades educacionales, sino por el temor de ser 
confundido con un homosexual o ser mal interpretado en razón de gestos, actitudes, modos o formas de ser.

De allí que no puede pasar inadvertida la actitud de algunos pocos jóvenes, especialmente mujeres, que además de reivindicar su derecho a una identidad propia distinta de la heterosexual promovida por la escuela, reivindiquen su derecho a expresar sus afectos en público del mismo modo que lo haría un joven heterosexual.

Con base en estos antecedentes se puede concluir que son aún muchos los desafíos que habrá de enfrentar el sistema educacional chileno en su propósito de combatir toda forma de discriminación y exclusión social, particularmente cuando ella dice relación no con simples prejuicios alojados en el discurso o prácticas sociales, sino en un sustrato ideológico más profundo que naturaliza, legitima y sacraliza la discriminación basado en la "creencia" de una supuesta superioridad de la heterosexualidad por sobre otras expresiones o modos de vivir la sexualidad.

Es decir, cualquier proyecto educativo inclusivo que atienda apenas a las consecuencias de la discriminación, pero no pretenda desarticular los dispositivos que están en la base de la homofobia, de la matriz patriarcal - machista o de la jerarquización de las sexualidades está necesariamente condenado al fracaso. Un proyecto exitoso es aquel que no se conforma con el reconocimiento, sino que aspira a la valoración de la diversidad como un bien que fundamenta y proporciona subsidios para un nuevo modo de relacionarse.

\section{REFERÊNCIAS}

ALONSO, Graciela.; MORGADE, Graciela. Educación, sexualidad, géneros: tradiciones teóricas y experiencias disponibles en un campo de construcción. In: ALONSO, Graciela.; MORGADE, Graciela (compiladoras). Cuerpos, sexualidades en la escuela: de la normalidad a la disidencia. Buenos Aires: Paidós, 2008.

AMERICAN EDUCATIONAL RESEARCH ASSOCIATION. Prevention of Bullying in Schools, Colleges and Universities. Washington, DC: American Educational Research Association, 2013.

BAKER, Jean. M. How homophobia hurts children nurturing diversity at home, at school and the community. New York: The Haworth Press, Inc, 2002.

BEER, David. Visiones y discursos en la educación física de la escuela primaria, In: MORGADE, Graciela.; ALONSO, Graciela (Comp.). Cuerpos, sexualidades en la escuela: de la normalidad a la disidencia. Buenos Aires: Paidós, 2008. p. 149-173. 
BENTO, Berenice.; FELIX - SILVA, Antônio. Desfazendo o gênero. Natal: Editora da UFRN, 2015.

BLUMENFELD, Warren. Homophobia: how we all pay the price. Boston: Beacon Press, 1992.

BORRILLO, Daniel. Homofobia. Barcelona: Ediciones Ballaterra, 2001.

BUTLER, Judith. Problemas de género: feminismo e subversão da identidade. 2 ed. Ed. Rio de Janeiro: Civilização Brasileira, 2008.

CONNELL, Raewyn. Masculinities. Berkeley: University of California Press, 1995.

CORNEJO, Juan. Jóvenes en la encrucijada. Última Década, CIDPA Valparaíso, $\mathrm{n}^{\circ} 32$, jul., 173-189, 2010.

ERIBÓN, Didier. Reflexiones sobre la cuestión gay, Barcelona: Anagrama, 2001.

DINIS, Nilson Fernandes. Homofobia e educação: quando a omissão também é signo de violência. Educar em Revista, n 39, p. 39-50, 2011.

GIMÉNEZ DE ABAD, Elvira. Cómo disminuir la agresividad en los niños: sugerencias para padres. Buenos Aires: Paidós, 2014.

GOODSON, Ivor. Historia del currículo. La construcción social de las disciplinas escolares. Barcelona: Pomares - Corredor, 1995.

INSTITUTO NACIONAL DE LA JUVENTUD - MINISTERIO DE DESARROLLO SOCIAL. Séptima Encuesta Nacional de Juventud, 2012. Disponivel em:

$<$ http://www.injuv.gob.cl/portal/septima-encuesta-nacional-de-juventud/> Acceso em: 15 Ago. 2017.

INSTITUTO NACIONAL DE LA JUVENTUD - MINISTERIO DE DESARROLLO SOCIAL. Octava Encuesta Nacional de Juventud, 2015. Disponivel em:

$<$ http://www.injuv.gob.cl/portal/wp-content/uploads//2017/03/libro-octava-encuestanacional-de-juventud.pdf $>$. Acceso em: 15 ago. 2017.

JUNQUEIRA, Rogerio Diniz. Pedagogía del armario: La normatividad en acción. Revista retratos de la escuela. Brasilia, v. 7, n 13, p. 481-498, 2013.

LOURO, Guacira Lopes. O corpo educado: pedagogías da sexualidade. Belo Horizonte: Autêntica, 2007.

MAGENDZO, Abraham.; GONZÁLEZ, Paola.; ROPERT, Teresa.; ESTÉVEZ, Catalina. Prevenir, atender y tratar el bullying. Bogotá: Transversales Magisterio, 2014.

MINEDUC. Encuesta Nacional de Convivencia Escolar, 2011. Disponivel em: $<$ http://www.mineduc.cl/usuarios/mineduc/doc/201207301558020.Encuesta_nacional_p revencion_agresion_acosoescolar_2011.pdf> Acceso em: 15 ago. 2017. 
MINEDUC. Ley 20. 536 Sobre Violencia Escolar, 8 de Septiembre de 2011.

Disponivel em: < https://www.leychile.cl/Navegar?idNorma=1030087>. Acceso em: 15 ago. 2017.

MINEDUC. Política Nacional de Convivencia Escolar: 2015 - 2018, 2015.

Disponivel em: $<$ http://www.mineduc.cl/2015/12/14/politica-nacional-de-convivenciaescolar/>. Acceso em: 15 ago. 2017.

MINISTERIO SECRETARÍA GENERAL DE GOBIERNO. Ley 20.609

Antidiscriminación, 12 de Julio de 2012. Disponivel em:

$<$ https://www.leychile.cl/Navegar?idNorma=1042092>. Acceso em: 15 ago. 2017.

NAVARRO - SWAIN, Tania. Desfazendo o "natural": a heterossexualidade compulsória e o continuum lesbiano. Revista Bagoas, n 5, p. 45-55, 2010.

NÚÑEZ, Guillermo. ¿Qué es la diversidad sexual? Reflexiones desde la academia y el movimiento ciudadano. Quito: Ediciones Abya - Yala, 2011.

PALMA, Irma; REYES, Daniela.; MORENO, Claudia. La educación sexual en Chile: Pluralismo y libertad de elección que esconde una propuesta gubernamental conservadora. Docencia, $n^{\circ}$ 49, p. 14-24, 2013.

PENNA, Melani.; MATEOS, Cristina. Los niveles de homofobia de los futuros docentes: una cuestión de derechos, salud mental y educación. Revista Iberoamericana de Educación, nº 66, p. 123-142, 2014.

PLATERO, Raquel. ¡Maricón el último! Docentes que actuamos. Revista d' estuis de la violencia, $\mathrm{n}^{\circ} 3$, p. 5-12, 2007.

PLATERO, Raquel.; GÓMEZ, Emilio. Herramientas para combatir el bullying homofóbico. Madrid: Talasa, 2008.

PÉREZ, Marchueta. Consecuencias del bullying homofóbico retrospectivo y los factores psicosociales en el bienestar psicológico de sujetos LGB. Revista de Investigación Educativa, v. 32, n. 1, p. 255-271, 2014.

POTEAT, Paul.; ESPELAGE, Dorothy.; KOENIG, Brian. Willingness to remain friends and attend school with lesbian and gay peers: Relational expressions of prejudice among heterosexual youth. Journal of Youth and Adolescence, v. 38, n. 7, p. 952-962, 2009.

RICH, Adriane. Heterossexualidade compulsoria e existencia lésbica. Revista Bagoas, $\mathrm{n}^{\circ} 5$, p. 17-44, 2010.

RIVERS, Ian. Homophobic bullying: research and theoretical perspectives. New York - Oxford: Oxford University Press, 2011. 
ROBINSON, Joseph.; ESPELAGE, Dorothy.; RIVERS, Ian. Developmental Trends in Peer Victimization and Emotional Distress in LGB and Heterosexual Youth. Pediatrics. v. 131, n 3, march, p. 423-430, 2013.

RUSSELL, Stephen. "Desafiando a homofobia nas escolas: políticas e programas para climas esclares seguros”. Educar em Revista. n³9, Curitiba - Brasil, jan./abr., p. 123138, 2011.

RUSSELL, Stephen.; SINCLAIR, Katerina; POTEAT, Paul; KOENIG, Brian. Adolescent Health and Harassement Based on Dsicriminatory Bias. American Journal Public Health. v. 12, $\mathrm{n}^{\circ}$ 3, march, p. 493-495, 2012.

SEDGWICK, Eve. Epistemología del armario, Barcelona: Ediciones de la Tempestad, 1998.

SILVA, Denise Braga da. Corpos extranhos se tornam materia: Identidades LGBT no currículo da escola. Curitiba: Editora CRV, 2014.

TOMAELLO, Flavia. Bullying: criar con confianza en una sociedad violenta. Buenos Aires: Editorial Albatros, 2014.

UNESCO. Respuestas del sector educación frente al bullying homofóbico. Cuadernillo 8. París: UNESCO, 2012.

VEIGA - NETO, A. De geometrías, currículo e diferenças. Educação \& Sociedade. Campinas, SP, n 79, p. 163-186, 2002.

ZYSMAN, M. Bullying: cómo prevenir e intervenir en situaciones de acoso escolar. Buenos Aires: Paidós, 2014.

\section{Como referenciar este artigo}

ESPEJO, Juan Cornejo. Discriminación por orientación sexual en el sistema escolar chileno: 2009 - 2016. Revista Ibero-Americana de Estudos em Educação, Araraquara, v. 13. n. esp. 2, p. 1471-1502, set., 2018. ISSN: 1982-5587. DOI: 10.21723/riaee.v13.nesp2.set2018.11656

Submetido em: 15/03/2018

Aprovado em: 19/06/2018 